\title{
Perioperative Antibiotic Prophylaxis in Laparoscopic Right Hemicolectomy for Colon Cancer: A 48-Hour Regimen
}

\author{
Haibin Zhang ${ }^{1}$, Xiongfei $\mathrm{Yu}^{1}$, Ketao $\mathrm{Jin}^{2}$, Lisong Teng ${ }^{1}$ \\ 'Department of Surgical Oncology, First Affiliated Hospital, \\ Zhejiang University School of Medicine, Hangzhou, 310003, Zhejiang Province, P. R. China \\ 'Department of Gastrointestinal Surgery, Shaoxing People's Hospital, \\ Shaoxing Hospital of Zhejiang University, Shaoxing, 312000, Zhejiang Province, P. R. China
}

\section{ABSTRACT}

Purpose: The standard protocol of perioperative antibiotic use in laparoscopic colectomy for colon cancer remains to be established. Given the ever-increasing number of antibiotic options available, as well as the growing problem of antibiotic resistance, there is a need for research on this important topic.

Methods: We retrospectively reviewed the clinical data of 45 patients receiving laparoscopic right hemicolectomy for colon cancer to investigate the occurrence of perioperative infections following laparoscopic surgery. This study included 45 cases receiving laparoscopic right hemicolectomy from January 2013 to December 2014. A 48-hour treatment of antibiotic prophylaxis was used.

Results: The incidence of incisional surgical site infection (SSI), organ/space SSI, and remote infection was retrospectively investigated. Incisional SSI occurred in $1(2.3 \%)$ patient. Organ/space SSI occurred in 1 (2.3\%) patient. No remote infection occurred.

Conclusions: The incidence of incisional SSI and organ/space SSI was low using a 48-hour treatment of antibiotic prophylaxis after laparoscopic right hemicolectomy for colon cancer. Therefore, the 48-hour protocol of prophylactic antibiotic treatment seems to be adequate for preventing perioperative infections in laparoscopic right hemicolectomy.

Key words: antibiotic prophylaxis, laparoscopic right hemicolectomy, colon cancer, surgical site infection (SSI), remote infection

\section{INTRODUCTION}

Colorectal cancer is one of the leading causes of mortality worldwide (1). Traditionally, cancers of the colon were removed through large abdominal incisions. Since the advent of laparoscopic surgery, it has become clear that patients benefit from a minimally invasive approach in a variety of ways (2). Therefore, laparoscopic-assisted surgery has been widely accepted as an alternative to conventional open surgery for colorectal cancer. Because of the
Corresponding author:

Ketao Jin, M.D.

Department of Gastrointestinal Surgery, Shaoxing People's Hospital, Shaoxing Hospital of Zhejiang University. No. 568 Zhongxing North Road, Shaoxing, 312000, Zhejiang Province, P.R. China

E-mail: jinketao2001@zju.edu.cn 
potential advantages, such as less invasiveness and postoperative pain, earlier recovery, better cosmetic results, milder morbidity, earlier time to walking, flatus, and oral intake, and quicker recovery with a shorter hospital stay, laparoscopic surgery for colorectal cancer was introduced into clinical practice in China in 2001 (3), was gradually implemented and is now commonplace in China. There has been booming interest in laparoscopic surgery for colorectal cancer since it was first described in 2001 (3). The last decade has witnessed national growth in the application of laparoscopic surgery for colorectal cancer yielding a significant amount of scientific data to support its clinical merits and advantages (4).

Surgical infections caused by the opening of contaminated cavities such as intestines, stomach or vagina have been feared by surgeons for many decades. It has been reported that wound infections occur in approximately $40 \%$ of patients undergoing colorectal surgery without antibiotic prophylaxis (5). Perioperative antibiotic use to prevent surgical site infection is a widely accepted procedure in general surgery, including laparoscopic surgery for colorectal cancer. Therefore different strategies have been developed to reduce the rate of complications associated to bacterial contamination. However, inappropriate antibiotic use increases environmental pressure favoring the emergence of antimicrobial-resistant bacteria that can cause surgical site infection, resulting in an increase in the cost of health care (6). A rational application of antibiotic agents is therefore essential and guidelines for appropriate use are currently under development. Results from the United States National Surgical Infection Prevention Project showed that among Medicare patients undergoing major surgery, antibiotic prophylaxis was begun within 1 hour before surgery in only $56 \%$ of patients and stopped within 24 hour of surgery in only $41 \%$, as recommended (7).

Surgical wounds were classified as clean (class I), clean-contaminated (class II), contaminated (class III) and dirty/infected (class IV) (8). According to this classification, laparoscopic right hemicolectomy is classified as clean-contaminated because the colon tract is opened. The optimal antibiotic prophylaxis for laparoscopic right hemicolectomy has not been investigated in China.

In this study, we retrospectively reviewed the clinical data of 45 patients receiving laparoscopic right hemicolectomy for colon cancer to investigate the occurrence of perioperative infections including incisional surgical site infection (SSI), organ/space SSI, and remote infection after a 48-hour antibiotic prophylaxis from January 2013 to December 2014.

\section{PATIENTS AND METHODS}

The institutional ethical committee approved the current retrospective study (Number: 20121220). A written informed consent was obtained from all patients. We reviewed the electronic medical records of consecutive patients receiving laparoscopic right hemicolectomy for colon cancer. From January 2013 to December 2014, 45 patients were included in this study. The length of skin incision ranged between 3 and $10 \mathrm{~cm}$ at the discretion of the operator and was $5 \mathrm{~cm}$ in the majority of patients. A standard laparoscopic right hemicolectomy was performed as previously described with slight modifications (9-11). A closed suction drain was not routinely placed in the pelvic cavity. Pubic hair was removed using a surgical clipper after general endotracheal anesthesia was performed. The first antibiotic was administered i.v. 30 min before the start of operation, while additional administration was given after the patient returned to the ward. Antibiotic prophylaxis for patients received laparoscopic right hemicolectomy for colon cancer was listed in table 1. Skin disinfection with povidone iodine and dressing exchange was performed daily from postoperative day 2. Incisional SSI, organ/space SSI, and remote infection were observed up to the patient's departure and

Table 1 - Antibiotic prophylaxis for patients received laparoscopic right hemicolectomy for colon cancer

\begin{tabular}{|c|c|c|}
\hline 48-hour treatment protocol & 48-hour treatment protocol if penicillin allergy & $\begin{array}{l}\text { Additional antibiotics used when surgical site infection } \\
\text { (SSI) or organ/space SSI was confirmed }\end{array}$ \\
\hline $\begin{array}{l}\text { (1) Cefuroxime sodium, } 1.5 \mathrm{~g} \text {, } \\
\text { i.v. } 30 \text { min before surgery and } \\
\text { continued twice daily up to } \\
\text { 48-hour postoperatively. }\end{array}$ & $\begin{array}{l}\text { (1) Clindamycin phosphate, } 0.6 \mathrm{~g} \text {, i.v. } 30 \text { min } \\
\text { before surgery and continued twice daily up to } \\
\text { 48-hour postoperatively. }\end{array}$ & $\begin{array}{l}\text { Cefuroxime sodium, } 1.5 \mathrm{~g} \text {, i.v. twice daily up to 6-day } \\
\text { postoperatively for the patient with incisional surgical site } \\
\text { infection (SSI). }\end{array}$ \\
\hline $\begin{array}{l}\text { (2) Metronidazole, } 1.0 \mathrm{~g} \text {, i.v. } \\
\text { twice daily up to } 48 \text {-hour } \\
\text { postoperatively. }\end{array}$ & $\begin{array}{l}\text { (2) Metronidazole, } 1.0 \mathrm{~g} \text {, i.v. twice daily up to } \\
\text { 48-hour postoperatively. }\end{array}$ & $\begin{array}{l}\text { Piperacillin Sulbactam Sodium, } 4.5 \mathrm{~g} \text {, i.v. three times daily } \\
\text { up to } 5 \text {-day postoperatively for the patient with organ/space } \\
\text { SSI. }\end{array}$ \\
\hline
\end{tabular}


followed-up for 30 days accordingly (8). Incisional SSI was defined as macroscopic abscess or purulent discharge observed on the operative wound. Organ/ space SSI was defined as infection in the organ subjected to surgery. Culture tests were performed using abscess or purulent discharge. Abscess or purulent discharge was qualitatively cultured for aerobes and anaerobes using standard laboratory techniques. Remote infections including respiratory infection and urinary tract infection were evaluated by chest plain films, sputum, urine, blood, or catheter culture after surgery. Data were presented as means and standard deviations (SD) for numerical variables and as frequencies, ratios or rates for categorical variables.

\section{RESULTS}

The clinical characteristics and short-term surgical outcomes of patients were listed in table 2. This study included 45 cases receiving laparoscopic right hemicolectomy from January 2013 to December 2014. A 48hour treatment of antibiotic prophylaxis was used (table 1). Incisional SSI occurred in 1 (2.3\%) patient. Organ/space SSI, intra-abdominal abscess, occurred in $1(2.3 \%)$ patient. No remote infection occurred. The patients with incisional SSI or organ/space SSI received additional antibiotics (table 1).

The causal microorganisms of incisional SSI and organ/space SSI were isolated and identified in these two patients. Microorganisms isolated in patient with incisional SSI were Staphylococcus epidermidis and S aureus as aerobes, whereas those in patient with organ/space SSI were Enterococcus faecalis.

The patient with incisional SSI did not develop fever, and were improved by removal of some sutures, abscess drainage and additional antibiotics. The patient with organ/space SSI developed fever and were treated with additional antibiotics as well as abscess drainage.

\section{DISCUSSION}

Postoperative infection causes various problems, such as prolongation of hospital stay, increase in medical costs and decrease in patient satisfaction (1214). Guidelines for the prevention of postoperative infection and proper antibiotic use have therefore been proposed by the Centers for Disease Control and Prevention (CDC) and other organizations $(8,15)$. In digestive tract surgery, the benefits of prophylactic antibiotic administration for prevention of SSI have been established (16-18). Based on the US guidelines, single-dose administration of an antibiotic within 1
Table 2 - Clinical characteristics and short-term surgical outcomes of patients received laparoscopic right hemicolectomy for colon cancer

\begin{tabular}{|c|c|}
\hline Characteristics & \\
\hline Patients (n) & 45 \\
\hline Age (years, mean $\pm S D)$ & $61.08 \pm 13.22$ \\
\hline Gender $(n, \%)$ & \\
\hline Male & $17(37.8)$ \\
\hline Female & $28(62.2)$ \\
\hline Surgical technique & $\begin{array}{l}\text { ultiport laparoscopic } \\
\text { ight hemicolectomy } \\
\text { nesocolic excision (TME) }\end{array}$ \\
\hline Conversion to open surgery (n, \%) & 0 \\
\hline Tumor locations (n, \%) & \\
\hline Cecum & $3(6.7)$ \\
\hline Ascending colon & $29(64.4)$ \\
\hline Hepatic flexure & $8(17.8)$ \\
\hline Transverse colon & $5(11.1)$ \\
\hline Operation time (minutes, mean \pm SD) & $142.56 \pm 30.46$ \\
\hline Estimated blood loss (mL, mean \pm SD) & $84.22 \pm 72.15$ \\
\hline Length of incision (cm, mean \pm SD) & $5.47 \pm 1.24$ \\
\hline Days to liquid diet (days, mean \pm SD) & $6.16 \pm 2.15$ \\
\hline Days to first flatus (days, mean \pm SD) & $3.33 \pm 1.26$ \\
\hline Days to first defecation (days, mean \pm SD) & $4.98 \pm 1.96$ \\
\hline Intraoperative complications (n, \%) & \\
\hline Massive hemorrhage $>500 \mathrm{ml}$ & 0 \\
\hline Organ injury & 0 \\
\hline lleus & 0 \\
\hline Post-operative complications ( $\mathrm{n}, \%)$ & \\
\hline Intestinal adhesion & 0 \\
\hline Anastomotic stenosis & 0 \\
\hline Anastomotic bleeding & 0 \\
\hline Anastomotic leakage & 0 \\
\hline Pulmonary infection & 0 \\
\hline Urinary tract infection & 0 \\
\hline Incisional surgical site infection (SSI) & $1(2.3)$ \\
\hline Organ/space SSI & $1(2.3)$ \\
\hline Postoperative mortality $(\mathrm{n}, \%)$ & 0 \\
\hline Hospital stay (days, mean \pm SD) & $13.78 \pm 5.42$ \\
\hline Tumor size (diameter, $\mathrm{cm}$, mean $\pm \mathrm{SD}$ ) & $5.68 \pm 2.29$ \\
\hline $\begin{array}{l}\text { Number of lymph node harvested } \\
(\mathrm{n}, \text { mean } \pm \mathrm{SD})\end{array}$ & $26.00 \pm 9.77$ \\
\hline $\begin{array}{l}\text { Number of positive lymph node harvested } \\
(n, \text { mean } \pm S D)\end{array}$ & $1.78 \pm 2.70$ \\
\hline RO resection $(0, \%)$ & $43(95.6)$ \\
\hline Proximal resection margin (cm, mean \pm SD) & $10.33 \pm 5.08$ \\
\hline Distal resection margin $(\mathrm{cm}$, mean $\pm \mathrm{SD})$ & $9.76 \pm 5.12$ \\
\hline Pathological types (n, \%) & \\
\hline Adenocarcinoma & $33(73.3)$ \\
\hline Mucinous adenocarcinoma & $11(24.4)$ \\
\hline Signet-ring cell carcinoma & $1(2.2)$ \\
\hline Tumor differentiation (n, \%) & \\
\hline Poor & $16(35.6)$ \\
\hline Moderate & $29(64.4)$ \\
\hline Well & 0 \\
\hline TNM stages $(\mathrm{n}, \%)$ & \\
\hline ' & $3(6.7)$ \\
\hline$\|$ & $19(42.2)$ \\
\hline III & $22(48.9)$ \\
\hline IV & $1(2.2)$ \\
\hline
\end{tabular}


Neoadjuvant chemotherapy (n, \%)

Adjuvant chemotherapy (n, \%) 0

Cost for operation (RMB, mean \pm SD) $7,528.65 \pm 1441.78$

Cost for drugs (RMB, mean \pm SD) $\quad 20,287.11 \pm 5311.30$

Total cost (RMB, mean \pm SD) $\quad 27,815.76 \pm 5427.74$

hour before surgery and the duration of administration within 24 hours after the end of surgery had been recommended, even in clean-contaminated surgery $(8$, 15). However, the Japanese Association for Infectious Diseases and the Japanese Society of Chemotherapy guidelines recommended the duration of prophylactic antibiotic administration should be 4 days or less in clean-contaminated surgery (19). Society of Infectious Diseases, Chinese Medical Association published guidelines in 2009, in which the duration of prophylactic antibiotic administration should be 48 hours or less in clean-contaminated surgery. However, the standard protocol of perioperative antibiotic use in laparoscopic colectomy for colon cancer has not been established. This is the first study to investigate the proper protocol of prophylactic antibiotic treatment for preventing perioperative infections in laparoscopic colectomy for colon cancer.

According to the guidelines for the prevention of SSI published by the US Centers for Disease Control and Prevention (CDC) in 1999, various factors such as age, nutritional status, diabetes, smoking and obesity are thought to be related to the occurrence of SSI (20). Surgical stresses can weaken the immune systems of patients during the perioperative period, resulting in immuno-compromise and an increased susceptibility to pathogens. Under these circumstances, SSI is well known as a major complication of gastrointestinal surgery. Presence of SSI does not only make the patients lose their satisfaction with their treatment as a result of prolonged hospitalization, but also substantially increase morbidity, mortality, and the cost of care (21). Several surveillance reports regarding SSI have been carried out and have played important roles in SSI prevention $(8,22,23)$. Patient factors (i.e., diabetes, smoking, obesity, steroid use, blood transfusion, etc.), environmental factors (i.e., ventilation in operating room, sterilization of surgical instruments, etc.), and bacterial factors are thought to be the main causes of SSI (24-30). Surgery of the colon is associated with a high incidence of SSI compared with surgery addressed to other parts of the digestive tract. Postoperative infection, including incisional SSI, organ/space SSI, or remote infection, occurs frequently after colorectal cancer surgery, causing not only a prolonged hospital stay and decrease in quality of life, but also a poorer prognosis due to the delay in postoperative treatment. When considering which antimicrobial agent to use, a surgeon considers the risk of wound infection, cost, the risk of a drug side effects, and antibiotic resistance. The Society of Infectious Diseases, Chinese Medical Association guidelines recommends use of antibiotics that are also effective against aerobes, as a single agent or in combination to prevent postoperative infection in colorectal surgery. The large variety of continuously newly developed antibiotics makes an adequate therapy difficult for non-specialists. It has been shown that a single shot prophylaxis of a standard combination is sufficient to prevent postoperative infections. In our clinical practice, a second-generation cephalosporin combined with metronidazole is mostly used (table 1).

The present study showed that the overall rate of incisional SSI and organ/space SSI in patients received laparoscopic right hemicolectomy was $2.3 \%$ and $2.3 \%$, respectively. No remote infection was found in these patients. Our results confirmed that the 48-hour protocol of prophylactic antibiotic treatment was adequate for preventing surgical site infection in laparoscopic right hemicolectomy. Our results suggest that a short perioperative course of antibiotics can adequately prevent remote infection. Patients with early postoperative fever should be evaluated to identify the possible source of infection. However, there is evidence that most of these episodes are of non-infectious origin (31).

\section{CONCLUSION}

Procedures for perioperative infection prophylaxis in laparoscopic colectomy for colon cancer consist of preoperative mechanical preparation, chemical preparation with oral antibiotic administration, and perioperative intravenous antibiotic administration. However, the optimal combination of these procedures and drugs and their durations of administration have not yet been established. Our results revealed that the incidence of incisional SSI and organ/space SSI was low using a 48-hour treatment of antibiotic prophylaxis after laparoscopic right hemicolectomy for colon cancer. Therefore, the 48-hour protocol of prophylactic antibiotic treatment seems to be adequate for preventing perioperative infections in laparoscopic right hemicolectomy. However, whether a 24-hour protocol of prophylactic antibiotic treatment would be enough to prevent perioperative infections in laparoscopic right hemicolectomy is not known and worth to be investigated in randomized control clinical trials further. 


\section{Authors' contributions}

HBZ designed and carried out this study, analysed the data and wrote this manuscript. XFY was involved in designing this study and in drafting the manuscript. KTJ and LST involved in designing this study and in drafting the manuscript. All authors read and approved the final manuscript.

\section{Acknowledgments}

This work was supported by National Natural Science Foundation of China (Grants No. 81374014 and No. 81472210) and Zhejiang Provincial Medical and Healthy Science and Technology Projects (Grant No. 2013KYA228).

\section{Conflict of interest}

The authors declare that they have no conflict of interest.

\section{REFERENCES}

1. Siegel R1, Naishadham D, Jemal A. Cancer statistics, 2013. CA Cancer J Clin. 2013 Jan;63(1):11-30.

2. Barkun JS, Barkun AN, Sampalis JS, Fried G, Taylor B, Wexler MJ, et al. Randomised controlled trial of laparoscopic versus mini cholecystectomy. The McGill Gallstone Treatment Group. Lancet. 1992 Nov 7:340(8828): 1116-9.

3. Chung CC1, Ha JP, Tsang WW, Li MK. Laparoscopic-assisted total mesorectal excision and colonic $\mathrm{J}$ pouch reconstruction in the treatment of rectal cancer. Surg Endosc. 2001 0ct;15(10):1098-101.

4. Jin K, Wang J, Lan H, Zhang R. Laparoscopic surgery for colorectal cancer in China: an overview. Int J Clin Exp Med. 2014 Dec 15;7(12): 4635-45.

5. Ludwig KA, Carlson MA, Condon RE. Prophylactic antibiotics in surgery. Annu Rev Med. 1993;44:385-93.

6. McGowan JE Jr. Cost and benefit of perioperative antimicrobial prophylaxis: methods for economic analysis. Rev Infect Dis. 1991 Sep-0ct;13 Suppl 10:S879-89.

7. Bratzler DW, Houck PM, Richards C, Steele L, Dellinger EP, Fry DE, et al. Use of antimicrobial prophylaxis for major surgery: baseline results from the National Surgical Infection Prevention Project. Arch Surg. 2005 Feb; 140(2):174-82.

8. Mangram AJ, Horan TC, Pearson ML, Silver LC, Jarvis WR. Guideline for prevention of surgical site infection, 1999. Hospital Infection Control Practices Advisory Committee. Infect Control Hosp Epidemiol. 1999 Apr; 20(4):250-78; quiz 279-80.

9. Cooperman AM1, Katz V, Zimmon D, Botero G. Laparoscopic colon resection: a case report. J Laparoendosc Surg. 1991 Aug;1(4):221-4.

10. Jacobs M, Verdeja JC, Goldstein HS. Minimally invasive colon resection (laparoscopic colectomy). Surg Laparosc Endosc. 1991 Sep;1(3):144-50.

11. Liu W, Li J, Jin K, Liu Q. Totally laparoscopic right colectomy: technique description. Hepatogastroenterology. 2015 Jan-Feb;62 (137):51-4.

12. Gaynes RP, Culver DH, Horan TC, Edwards JR, Richards C, Tolson JS Surgical site infection (SSI) rates in the United States, 1992-1998: the National Nosocomial Infections Surveillance System basic SSI risk index. Clin Infect Dis. 2001;33 Suppl 2:S69-77.

13. Astagneau P, Rioux C, Golliot F, Brücker G; INCISO Network Study Group. Morbidity and mortality associated with surgical site infections: results from the 1997-1999 INCISO surveillance. J Hosp Infect.
2001 Aug;48(4):267-74

14. Kirkland KB1, Briggs JP, Trivette SL, Wilkinson WE, Sexton DJ. The impact of surgical-site infections in the 1990s: attributable mortality, excess length of hospitalization, and extra costs. Infect Control Hosp Epidemiol. 1999 Nov;20(11):725-30.

15. Bratzler DW, Houck PM; Surgical Infection Prevention Guidelines Writers Workgroup; American Academy of Orthopaedic Surgeons; American Association of Critical Care Nurses; American Association of Nurse Anesthetists, et al. Antimicrobial prophylaxis for surgery: an advisory statement from the National Surgical Infection Prevention Project. Clin Infect Dis. 2004 Jun 15;38(12):1706-15.

16. Stone HH, Haney BB, Kolb LD, Geheber CE, Hooper CA. Prophylactic and preventive antibiotic therapy: timing, duration and economics. Ann Surg. 1979 Jun;189(6):691-9.

17. Baum ML, Anish DS, Chalmers TC, Sacks HS, Smith H Jr, Fagerstrom RM. A survey of clinical trials of antibiotic prophylaxis in colon surgery: evidence against further use of no-treatment controls. N Engl J Med. 1981 Oct 1;305(14):795-9.

18 Guglielmo BJ, Hohn DC, Koo PJ, Hunt TK, Sweet RL, Conte JE Jr. Antibiotic prophylaxis in surgical procedures. A critical analysis of the literature. Arch Surg. 1983 Aug;118(8):943-55.

19 Suzuki T, Sadahiro S, Maeda Y, Tanaka A, Okada K, Kamijo A. Optimal duration of prophylactic antibiotic administration for elective colon cancer surgery: A randomized, clinical trial. Surgery. 2011 Feb;149(2): 171-8.

20 Mangram AJ, Horan TC, Pearson ML, Silver LC, Jarvis WR. Guideline for Prevention of Surgical Site Infection, 1999. Centers for Disease Control and Prevention (CDC) Hospital Infection Control Practices Advisory Committee. Am J Infect Control. 1999 Apr;27(2):97-132; quiz 133-4; discussion 96.

21 Collins TC, Daley J, Henderson WH, Khuri SF. Risk factors for prolonged length of stay after major elective surgery. Ann Surg. 1999 Aug; 230(2): 251-9.

22 Sørensen LT, Hemmingsen U, Kallehave F, Wille-Jørgensen P, Kjaergaard J, Møller LN, et al. Risk factors for tissue and wound complications in gastrointestinal surgery. Ann Surg. 2005 Apr; 241(4):654-8

23 Saito T, Aoki Y, Ebara K, Hirai S, Kitamura Y, Kasaoka Y, et al. Surgicalsite infection surveillance at a small-scale community hospital. J Infect Chemother. 2005 Aug;11(4):204-6.

24 Classen DC, Evans RS, Pestotnik SL, Horn SD, Menlove RL, Burke JP. The timing of prophylactic administration of antibiotics and the risk of surgical-wound infection. N Engl J Med. 1992 Jan 30;326 (5):281-6.

25 Ishida H, Yokoyama M, Nakada H, Inokuma S, Hashimoto D. Impact of oral antimicrobial prophylaxis on surgical site infection and methicillin-resistant Staphylococcus aureus infection after elective colorectal surgery. Results of a prospective randomized trial. Surg Today. 2001;31(11):979-83.

26 Takesue Y, Yokoyama T, Akagi S, Ohge H, Murakami Y, Sakashita Y, et al. A brief course of colon preparation with oral antibiotics. Surg Today. 2000; 30(2):112-6.

27 Morita S, Nishisho I, Nomura T, Fukushima Y, Morimoto T, Hiraoka N, et al. The significance of the intraoperative repeated dosing of antimicrobials for preventing surgical wound infection in colorectal surgery. Surg Today. 2005;35(9):732-8.

28 Miettinen RP, Laitinen ST, Mäkelä JT, Pääkkönen ME. Bowel preparation with oral polyethylene glycol electrolyte solution vs. no preparation in elective open colorectal surgery: prospective, randomized study. Dis Colon Rectum. 2000 May;43(5):669-75; discussion 675-7.

29 Zmora 0, Pikarsky AJ, Wexner SD. Bowel preparation for colorectal surgery. Dis Colon Rectum. 2001 Oct;44(10):1537-49.

30. Zmora O, Mahajna A, Bar-Zakai B, Rosin D, Hershko D, Shabtai M, et al. Colon and rectal surgery without mechanical bowel preparation: a randomized prospective trial. Ann Surg. 2003 Mar;237(3):363-7.

31 Garibaldi RA, Brodine S, Matsumiya S, Coleman M. Evidence for the non-infectious etiology of early postoperative fever. Infect Control. $1985 \mathrm{Jul} ; 6(7): 273-7$. 